\title{
Article
}

\section{SiC-C Composite as A Highly Stable and Easily Regenerable Photothermal Material for Practical Water Evaporation}

\author{
Le Shi, Yusuf Shi, Renyuan Li, Jian Chang, Noor Zaouri, Elaf Ali \\ Ahmed, Yong Jin, Chenlin Zhang, Sifei Zhuo, and Peng Wang
}

ACS Sustainable Chem. Eng., Just Accepted Manuscript • DOI: 10.1021/

acssuschemeng.7b04695 - Publication Date (Web): 25 May 2018

Downloaded from http://pubs.acs.org on May 29, 2018

\section{Just Accepted}

"Just Accepted" manuscripts have been peer-reviewed and accepted for publication. They are posted online prior to technical editing, formatting for publication and author proofing. The American Chemical Society provides "Just Accepted" as a service to the research community to expedite the dissemination of scientific material as soon as possible after acceptance. "Just Accepted" manuscripts appear in full in PDF format accompanied by an HTML abstract. "Just Accepted" manuscripts have been fully peer reviewed, but should not be considered the official version of record. They are citable by the Digital Object Identifier (DOI®). "Just Accepted" is an optional service offered to authors. Therefore, the "Just Accepted" Web site may not include all articles that will be published in the journal. After a manuscript is technically edited and formatted, it will be removed from the "Just Accepted" Web site and published as an ASAP article. Note that technical editing may introduce minor changes to the manuscript text and/or graphics which could affect content, and all legal disclaimers and ethical guidelines that apply to the journal pertain. ACS cannot be held responsible for errors or consequences arising from the use of information contained in these "Just Accepted" manuscripts. 
1 SiC-C Composite as A Highly Stable and Easily Regenerable Photothermal Material for Practical Water Evaporation

3 Le Shi, Yusuf Shi, Renyuan Li, Jian Chang, Noor Zaouri, Elaf Ahmed, Yong Jin, Chenlin

$4 \quad$ Zhang, Sifei Zhuo and Peng Wang*

5 Water Desalination and Reuse Center, Division of Biological and Environmental Sciences and

6 Engineering, King Abdullah University of Science and Technology, Thuwal 23955-6900, Saudi

$7 \quad$ Arabia. E-mail: peng.wang@,kaust.edu.sa

\section{ABSTRACT}

10 Solar-driven water distillation by photothermal materials is emerging as a promising way of 11 renewable energy-driven clean water production. In designing photothermal materials, light 12 absorption, photo-to-thermal conversion efficiency, and ability to localize thermal energy at 13 the water-air interface are three important considerations. However, one additional 14 consideration, regenerability, has so far slipped out of the photothermal material designs at 15 status quo. This work reveals that there is a fouling layer formed during photothermal 16 evaporation of real seawater (Red Sea water) and domestic wastewater, which once formed, 17 would be difficult to remove. Herein, we synthesize a SiC-C composite monolith as an 18 effective photothermal material where carbon acts as photothermal component and SiC serves 19 as a heat conductor and strong structural support. The high mechanical strength of the 20 monolithic composite makes it able to withstand repeatedly high strength physical cleaning by 21 brush scrubbing and sonication and the anti-carbon-loss mechanism generates zero carbon 22 loss during the physical cleaning. In the case of the domestic wastewater evaporation, the bio- 
23 and organic foulants on the $\mathrm{SiC}-\mathrm{C}$ composite monolith can be totally removed by annealing at

$241000{ }^{\circ} \mathrm{C}$ in $\mathrm{N}_{2}$ atmosphere. We believe that the $\mathrm{SiC}-\mathrm{C}$ composite monoliths are promising

25 photothermal materials in practical solar-driven water evaporation applications thanks to their

26 highly stable and easily regenerable properties and therefore more research efforts are

27 warranted to further improve their performances.

\section{KEYWORDS}

29 Solar-driven water evaporation; photothermal material; SiC-C monolith; foulant cleaning; high 30 mechanical strength; thermal stability

\section{INTRODUCTION}

32 Solar-driven water distillation, which directly uses solar energy to generate water vapor and

33 then collects condensate as fresh water, is emerging as a promising way of renewable energy-

34 driven clean water production. ${ }^{1-3}$ It is able to produce fresh water from a variety of water

35 sources, is attractive and economical especially for small sized water plants, and can be made

36 into point-of-use potable water production apparatus. An effective photothermal material is a

37 key to a successful solar-driven water distillation design. Recently, many photothermal

38 materials have been developed and showed good photo-to-thermal conversional capability,

39 such as carbon based material, ${ }^{4-8}$ plasmonic particles, ${ }^{9-12}$ organic polymers, ${ }^{13}$ along with many 40 emerging new materials. ${ }^{14-16}$

41 In designing photothermal materials, high solar light absorption, high photo-to-thermal 42 conversion efficiency, and ability to localize thermal energy at the water-air interface are 43 three important considerations. However, one additional consideration, foulant cleaning 44 strategy, has so far slipped out of the photothermal material design due to the fact that in the 
45 majority of the previous works, instead of natural waters, pure water or synthetic seawater $46(3.5 \% \mathrm{NaCl})$, was used as surrogate to prove the energy efficiency of the photothermal 47 materials.

48 As known, the composition of natural water is much more complex than pure water or 49 synthetic seawater. The natural water generally contains such species as bacteria, dissolved 50 organic and inorganic species, etc., which would lead to material fouling. ${ }^{17-21}$ Fouling is 51 generally defined as the accumulation of unwanted compounds/substances on a material's 52 surface, which is one of the biggest concerns in all kinds of water treatment processes and 53 degrades the performance and shortens the service lifetime of the materials. Thus, in practical 54 solar-driven water evaporation applications, the photothermal materials would have to face 55 the similar fouling problems to other water treatment processes. Therefore, regenerable 56 property should be considered in any photothermal material intended for practical solar-driven 57 water evaporation, which unfortunately is missing in the majority of the previous 58 photothermal materials. Envisioning typical foulants in solar-driven water evaporation, a 59 photothermal material ought to be mechanically strong to withstand washing with flushing 60 water, periodical physical cleaning/brushing or sonication, and potential heat treatment to 61 remove biomass as basic foulant cleaning approaches. ${ }^{22-25}$

62 In the previous photothermal designs, composite materials are typically fabricated in which

63 light-adsorbing materials are physically deposited onto a porous structural support, such as 64 paper, ${ }^{11}$ metal mesh, ${ }^{13}$ macrosporous silica, ${ }^{4}$ AAO membrane, ${ }^{26}$ wood, ${ }^{5}$ etc. The necessity of 65 the porous substrates is due to their ability to enhance light absorption by reducing light 66 reflection and to increase the material/water interface for fast heat transfer. However, the 67 weak interaction between the light-adsorbing materials and the structural support makes the 
68 light-adsorbing materials easily come off the substrate during applications and also many of

69 porous substrate supports are not mechanically strong enough, both of which would lead to

70 these photothermal materials not able to withstand the basic foulant cleaning measures as

71 listed above.

72 In searching for a porous support substrate suitable for practical photothermal applications,

73 we were attracted by porous ceramics, which typically possess such desirable properties as

74 high mechanical strength, excellent corrosion resistance, low cost, and desirable porous

75 structure, etc. These attractive properties have led porous ceramics to various applications,

76 including catalyst supports, heat exchangers, filters, among others. ${ }^{27}$

77 Recently, porous silicon carbide $(\mathrm{SiC})$ ceramics have been intensively studied due to their

78 excellent mechanical and chemical stability, low density, high thermal shock resistance, and

79 excellent corrosion resistance at high temperature. ${ }^{28-30}$ Very fortunately, during the

80 preparation of $\mathrm{SiC}$ ceramics, carbon, a highly effective light-absorbing material, is typically

81 coproduced as by-product, which makes the commercial products of SiC appear deep black.

82 The carbon content in the $\mathrm{SiC}$ ceramics is generally uniformly distributed and more

83 importantly is locked within the skeleton of $\mathrm{SiC}$, thus representing an effective anti-carbon-

84 particle loss mechanism. ${ }^{29,} 31$ Therefore, we believe that $\mathrm{SiC}$ and carbon composite (SiC-C)

85 have a possibility of being a good photothermal material with a highly stable property.

86 Herein, we rationally design a $\mathrm{SiC}-\mathrm{C}$ composite monolith as an effective photothermal

87 material where carbon acts as the light absorber and heat converter and SiC serves as a heat

88 conductor and strong structural support. The high mechanical strength of the monolithic

89 composite makes it able to withstand repeatedly high strength physical cleaning by brush

90 scrubbing and sonication and the anti-carbon-loss mechanism generates zero carbon loss 
91 during the physical cleaning. Moreover, this work, for the first time, reveals that the natural

92 seawater (Red Sea water) would form on the photothermal material surface the precipitation

93 of $\mathrm{CaCO}_{3}, \mathrm{MgCO}_{3}$ and $\mathrm{CaSO}_{4}$, which, once formed, are difficult to totally remove by simple

94 water flushing. In the case of the domestic wastewater evaporation, the bio- and organic

95 foulants on the SiC-C composite monolith can be totally removed by annealing at $1000{ }^{\circ} \mathrm{C}$ in

$96 \mathrm{~N}_{2}$ atmosphere. We believe that the $\mathrm{SiC}-\mathrm{C}$ composite monoliths are promising photothermal

97 materials in practical solar-driven water evaporation applications thanks to their highly stable

98 and easily regenerable properties and therefore more research efforts are warranted to further

99 improve their performances.

100

101

\section{EXPERIMENTAL SECTION}

102 Chemicals and materials. Small sized silicon carbide (SiC, small particle, beta-phase, 103 nanopowder, 45-55 nm, 70-90 $\mathrm{m}^{2} \mathrm{~g}^{-1}$, Alfa Aesar), large-sized silicon carbide (SiC, big 104 particle, beta-phase, 99.8\%, metals basis, 1 micron, $14-19 \mathrm{~m}^{2} \mathrm{~g}^{-1}$, Alfa Aesar), 105 polycarbomethylsilane (PCMS, Sigma-Aldrich), aluminum oxide $\left(\mathrm{Al}_{2} \mathrm{O}_{3}, 40-50 \mathrm{~nm}, 99.5 \%\right.$, 106 Alfa Aesar), yeast extract (Fluka), glutinous rice flour (AFTA brand, from Shaflout Group) 107 and toluene (Fluka) were used in this work. Commercial synthetic seawater (ASTM D114) 108 was from RICCA Company. All of the chemicals were purchased and used without further 109 purification.

110 Fabrication of tandem-structured $\mathrm{SiC}$ ceramic monolith composite. $\mathrm{SiC}-\mathrm{C}$ composite 111 monolith was synthesized following a literature method, which used PCMS as a preceramic 112 polymer and SiC mixture of two sized powers (namely, 45-55nm and 1 micron) as the 
113 precursor. In a typical synthesis, $1.4 \mathrm{~g}$ large sized SiC powder (1 micron) and $0.6 \mathrm{~g}$ small 114 sized SiC powder (45-55 nm) were mixed with 0.4 g PCMS in an onyx mortar and then 115 dissolved within $20 \mathrm{ml}$ toluene. It is worth mentioning that PCMS in the synthesis is both 116 carbon precursor and also acts as cross linker. ${ }^{32-35}$ The gray colored paste-like mixture was 117 evaporated on a $60^{\circ} \mathrm{C}$ hotplate to generate gray powdery composite. The dried composite was 118 then ground along with $0.1 \mathrm{~g} \mathrm{Al}_{2} \mathrm{O}_{3}$ powder in the onyx mortar, followed by sieving by 400 119 mesh. $\mathrm{Al}_{2} \mathrm{O}_{3}$ in this synthesis is a sintering aid, which makes possible of fabricating highly 120 dense $\mathrm{SiC}$ monolith at a reduced temperature. ${ }^{36-37}$

121 To make a tandem structure of $\mathrm{SiC}$, a sacrificial template method was used. ${ }^{38}$ Different 122 quantities of yeast $(0.03 \mathrm{~g}, 0.06 \mathrm{~g}, 0.09 \mathrm{~g}$ and $0.12 \mathrm{~g})$ and rice flour powder $(0.03 \mathrm{~g}, 0.06 \mathrm{~g}$, $1230.09 \mathrm{~g}$ and $0.12 \mathrm{~g}$ ) as the sacrificial templates were mixed with $0.45 \mathrm{~g}$ sieved $\mathrm{SiC}$ powders.

124 The remaining sieved $\mathrm{SiC}$ powders were first transferred into an empty stainless steel mold 125 (inner diameter $=4 \mathrm{~cm}$ ) on top of which the mixture with the yeast and rice flour was then 126 added. The mixed powders were compressed into a tablet-like monolith under a pressure of 80 $127 \mathrm{MPa}$ for $20 \mathrm{~min}$. Then the compressed monolith composite was transferred into a horizontal 128 ceramic tube furnace and subjected to a thermal treatment in $\mathrm{N}_{2}$ atmosphere at $1200{ }^{\circ} \mathrm{C}$ for 2 129 hours with a temperature ramp of $2^{\circ} \mathrm{C} \min ^{-1}$. The heat treatment removed the sacrificial 130 template and thus generated monolithic $\mathrm{SiC}-\mathrm{C}$ tandem structured composite having a porous 131 top layer and a dense bottom layer. The tandem-structured SiC-C monoliths prepared with 132 different quantities of templates were denoted as $\mathrm{SiC}-\mathrm{C}(0.03 \mathrm{y}+0.03 \mathrm{r}), \mathrm{SiC}-\mathrm{C}(0.06 \mathrm{y}+0.06 \mathrm{r})$, $133 \mathrm{SiC}-\mathrm{C}(0.09 \mathrm{y}+0.09 \mathrm{r})$ and $\mathrm{SiC}-\mathrm{C}(0.12 \mathrm{y}+0.12 \mathrm{r})$.

134 For a comparison, a single layer SiC-C composite monolith with a uniformly dense structure 135 was synthesized in the absence of any sacrificial templates, denoted as SiC-C dense, while a 
136 single layer $\mathrm{SiC}-\mathrm{C}$ composite monolith with a uniformly porous structure, denote as SiC-C 137 porous, was also prepared by mixing the sacrificial templates with all the sieved powders, 138 following otherwise the same conditions.

139 Material characterization. Scanning electron microscopy (SEM, FEI Quanta 600) was used 140 to characterize the morphology and powder X-ray diffraction (XRD, Bruker D8 Discover 141 diffractometer) was used to characterize the crystal properties of the samples. The scanning of $1422 \theta$ angle (degree) was made in the range of $20^{\circ}$ to $80^{\circ}$ with a scanning rate of $2.5^{\circ} / \mathrm{min}$. 143 Optical microscope (Olympus BX51, 5x, Olympus) was used to get the microscopic images 144 of the surface of materials and also get the observation of the fouling layers on the surface of 145 materials. Thermal gravimetric analysis (TGA, NETZSCH) was carried out in the range of $146 \quad 25-1000{ }^{\circ} \mathrm{C}$ at a heating rate of $5^{\circ} \mathrm{C} \mathrm{min}^{-1}$.

147 The UV/visible/infrared reflectance properties of the materials were measured using a 148 spectrophotometer equipped with an integration sphere (UV-Vis-IR Cary 5000), with fine $149 \mathrm{BaSO}_{4}$ powder as a reference baseline in the spectral range of $300-2000 \mathrm{~nm}$ at room 150 temperature. Raman spectra were obtained on a Horiba Aramis, with a $473 \mathrm{~nm}$ laser 151 wavelength excitation. Fourier transforms infrared (FTIR) spectroscopy was measured in the 152 absorption mode within the scanning range from 650 to $4000 \mathrm{~cm}^{-1}$ using an FTIR 153 spectrometer (Thermo Scientific-Nicolet 8700). Contact angles were obtained by using an 154 OCA 35 (Data-Physics, Filderstadt, Germany). Thermal images and temperature gradients 155 were collected using an infrared camera (FLIR A655).

156 Water evaporation performance measurement. A solar simulator was used to provide the 157 solar irradiation (Oriel Sol1A Class ABB Solar simulators, Newport) with an intensity of one 158 sun $\left(\mathrm{AM} 1.5,1000 \mathrm{Wm}^{-2}\right)$. A homemade system was used in the water evaporation 
159 performance measurements ${ }^{8}$. In more details, a cylindrical polystyrene (PS) container with a 160 mouth diameter of $4.2 \mathrm{~cm}$ was filled with the test source water. The SiC-C composite 161 monolith was put on top of an expanded polystyrene foam (PS) substrate, which made it able 162 to float on the surface of water. In this work, two strips of orthometric cotton cloth were 163 wrapped onto the SiC-C monolith together with PS substrate. The cotton cloth was immersed 164 in the bulk water. The water container was placed on an electronic analytical scale to monitor 165 real-time water mass loss due to evaporation. A white paper board was used as a cover around 166 the measurement system to minimize the effect of the ambient airflow turbulence.

\section{RESULTS AND DISCUSSION}

169 The $\mathrm{SiC}$ is designed to have a monolithic tandem structure with a porous top layer and a 170 dense bottom layer and this structure is beneficial to improve light absorbance ${ }^{39-40}$ and at the 171 same time to give the structure a strong mechanical property and thus ability to withstand 172 strong physical forces during physical cleaning (Figure 1).

173 In the synthesis of SiC-C monolith in this work, $\mathrm{Al}_{2} \mathrm{O}_{3}$ is used as a sintering aid, which 174 effectively lowers the calcination temperature to $1200{ }^{\circ} \mathrm{C}$ from otherwise $1500{ }^{\circ} \mathrm{C}$ without the 175 sintering aid. PCMS is the carbon source in the synthesis and it also acts as cross linkers, 176 which help the cross-linking and thus the generation of compact $\mathrm{SiC}$ monolith. The synthesis 177 procedure of the tandem-structured SiC-C composite monolith is presented in Figure S1. 


\section{9}

180 Figure 1 The conceptual diagram showing the design of SiC-C composite monolith, its fouling during practical 181 water evaporation and the foulant cleaning approaches.

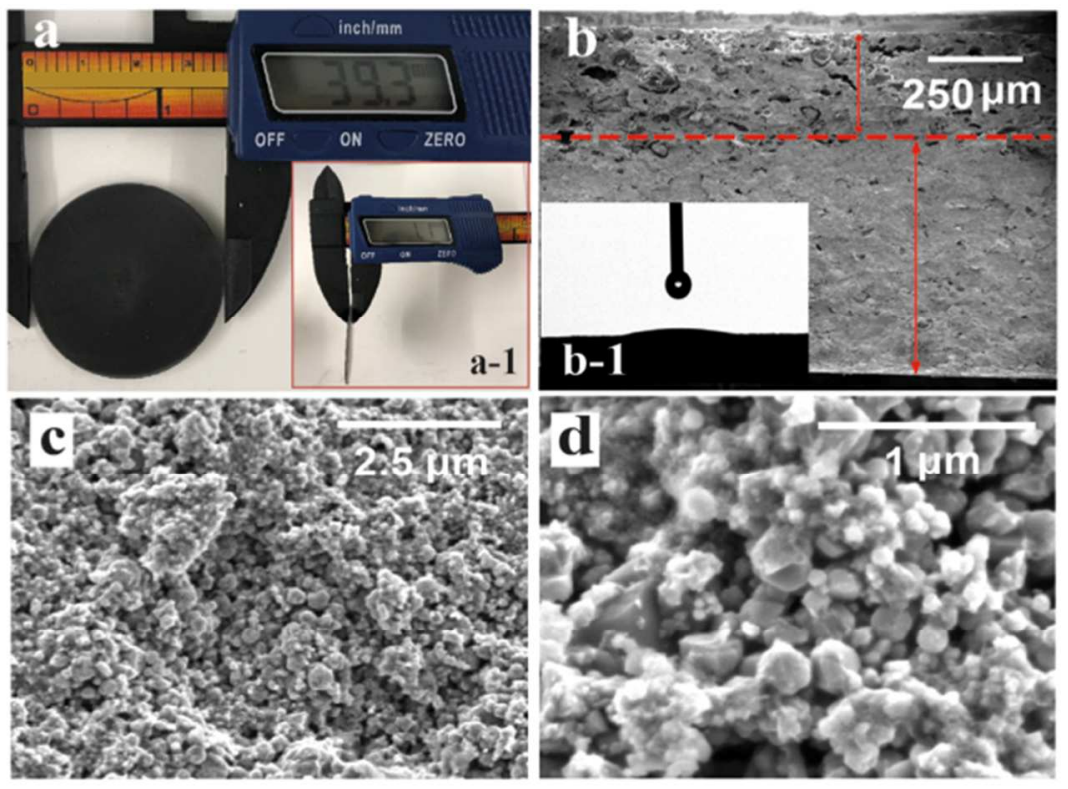

182 Figure $2(1)$ digital photos of SiC-C $(0.09 \mathrm{y}+0.09 \mathrm{r})$ monolith showing its diameter and thickness. (b) SEM images 183 of cross-section of $\mathrm{SiC}-\mathrm{C}(0.09 \mathrm{y}+0.09 \mathrm{r})$ monolith. Inset in Figure $2 \mathrm{~b}$ is the contact angle of the surface of SiC-C 
$184(0.09 \mathrm{y}+0.09 \mathrm{r})$ monolith $\left(\sim 10^{\circ}\right)$. (c) and (d) the zoomed-in images of the bottom dense layer of SiC-C $(0.09 \mathrm{y}$ $185+0.09$ r) monolith.

186 The samples prepared with different amount of two kinds of sacrificial templates (Figure S2 187 and S3) are presented and discussed in Supporting Information (SI) (Figure S4, S5, S6 and 188 S7). Two different sizes of SiC precursor powders are used in order to get a compact structure 189 and the sizes of the $\mathrm{SiC}$ precursor powders are presented in Figure S8. All the samples have 190 the same diameter of $\sim 3.93 \mathrm{~cm}$ and thickness of $\sim 1.1 \mathrm{~mm}$ (Figure $2 \mathrm{a}$ ), which appears visually 191 deep black. From the cross-sectional SEM image of SiC-C $(0.09 y+0.09 r)$ (Figure 2b), a clear 192 boundary between the top porous layer $(\sim 300 \mu \mathrm{m}$ thickness $)$ and the bottom dense layer $(\sim 800$ $193 \mu \mathrm{m}$ thickness) can be seen. The porous top layer expectedly consists of macro-pores (1-70 $\mu \mathrm{m})$ 194 while the bottom dense layer contains only nano-pores (50-400 nm). As comparisons, single 195 layered dense (Figure S5a) and porous (Figure S5f) SiC-C monoliths are prepared, showing 196 relatively uniform pores thorough the entire monoliths. Inset in Figure $2 \mathrm{~b}$ shows that the 197 surface of $\mathrm{SiC}-\mathrm{C}$ monolith is hydrophilic with a contact angle of $10^{\circ}$.
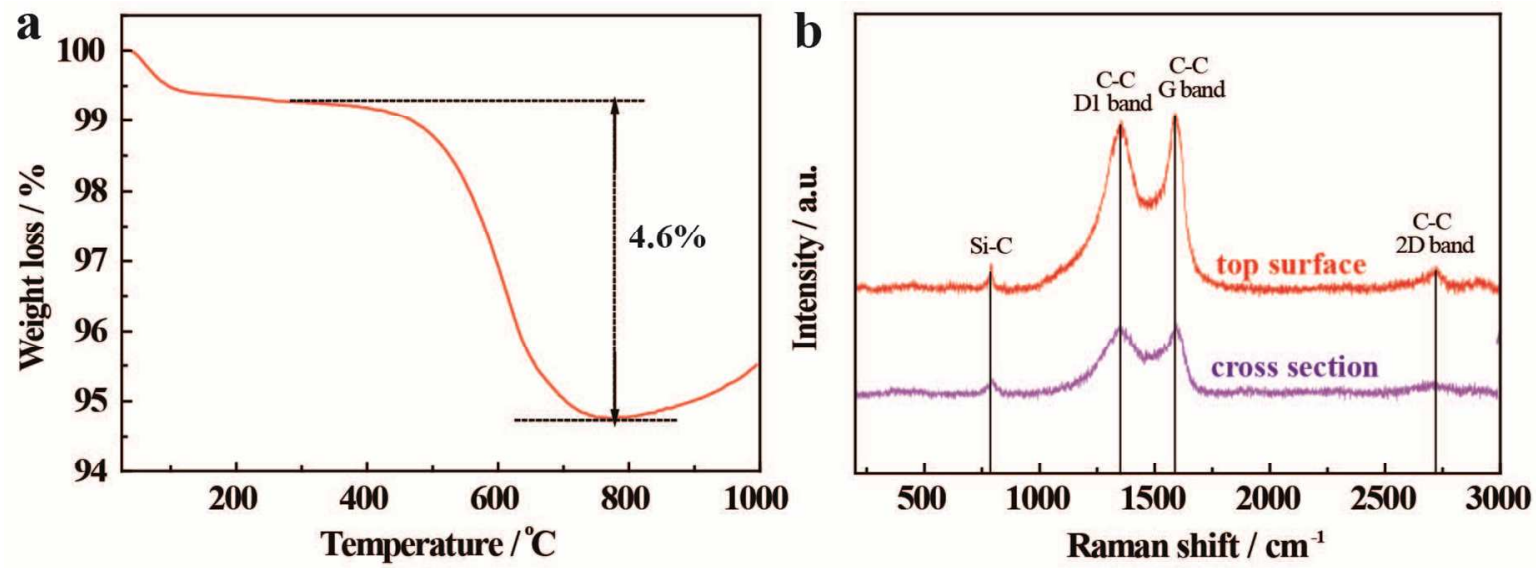

199 Figure 3 (a) TGA curve of $\mathrm{SiC}-\mathrm{C}(0.09 \mathrm{y}+0.09 \mathrm{r})$ monolith in air atmosphere in the temperature range of 25$2001000^{\circ} \mathrm{C}$, with a heating rate of $5^{\circ} \mathrm{C} / \mathrm{min}$. (b) Raman spectra of SiC-C $(0.09 \mathrm{y}+0.09 \mathrm{r})$ monolith measured with 473 $201 \mathrm{~nm}$ laser wavelength excitation, obtained from the top surface and the cross sectional surface. 
202 The crystalline phases present in the raw $\mathrm{SiC}$ powders as well as in the sintered ceramic SiC203 C composite monolith are identified by X-ray powder diffraction (XRD) in Figure S9. XRD 204 spectra of $\mathrm{SiC}$ precursor powders and the monolithic samples annealed at $1200{ }^{\circ} \mathrm{C}$ show that 205 the SiC-C monolith samples are single phase, having the crystal structure of $\beta$-SiC (JCPDS 206 74-2307). No peaks related to the isolated hexagonal SiC polytypes are observed.

207 The amount of free carbon content, which is photothermal component, of SiC-C monolith is 208 investigated through thermal air-oxidation behavior of the residue obtained from TGA curve 209 (Figure 3a). The TGA curve in the temperature range of $25-1000{ }^{\circ} \mathrm{C}$ shows the succession of 210 two steps. The initial weight loss $(4.6 \%)$ occurring in the $310-776{ }^{\circ} \mathrm{C}$ temperature range is 211 assigned to the air oxidation of the free carbon, which indicates the content of free carbon in 212 SiC-C $(0.09 \mathrm{y}+0.09 \mathrm{r})$ monolith is sufficiently high and around $4.6 \%$. The weight increase 213 above $776^{\circ} \mathrm{C}$ is due to air-oxidation of $\mathrm{SiC}$ into $\mathrm{SiO}_{2}$ as determined by XRD (Figure $\mathrm{S} 10$ ). The 214 amount of free carbon in our case is a good compromise between light absorption and 215 material's hardness. The free carbon content in the synthesis of SiC-C composite can be 216 potentially adjusted, but it can drastically affect the hardness and mechanical strength of SiC-C 217 monolith far beyond a simple effect of porosity. ${ }^{31}$ The carbon content is not adjusted in this 218 work given the good balance of the light absorption and mechanical robustness of our SiC-C 219 monolith.

220 Carbon structure is determined by Raman spectroscopy with a $473 \mathrm{~nm}$ laser wavelength 221 excitation. The set of two large bands located at $1358 \mathrm{~cm}^{-1}$ (D1 band) and $1593 \mathrm{~cm}^{-1}$ (G band) 222 is typically encountered for an amorphous structure of carbon. Raman spectra obtained from 223 the top surface and the cross-section of the monolith show the similar typical bands from C-C, 224 meaning that the free carbon in tandem-structured SiC-C monolith distributes quite uniformly. 
225 For comparisons, Raman spectra of SiC precursor powders are also presented in Figure S11.

226 Regarding the chemical stability, a sample of SiC-C monolith is immersed in sulfuric acid $227(0.2 \%)$, nitric acid $(0.3 \%)$ and $\mathrm{NaOH}(0.4 \%)$, respectively. ${ }^{41}$ Judging from the photos taken 228 before and after the chemical treatment (Figure S12), SiC-C corrosion is observed after $\mathrm{NaOH}$ 229 treatment, however, there was not obviously visual difference in the appearance of the sample 230 after acid treatment, which shows its stability in acid and is in agreement with the literature 231 results. $^{42-43}$
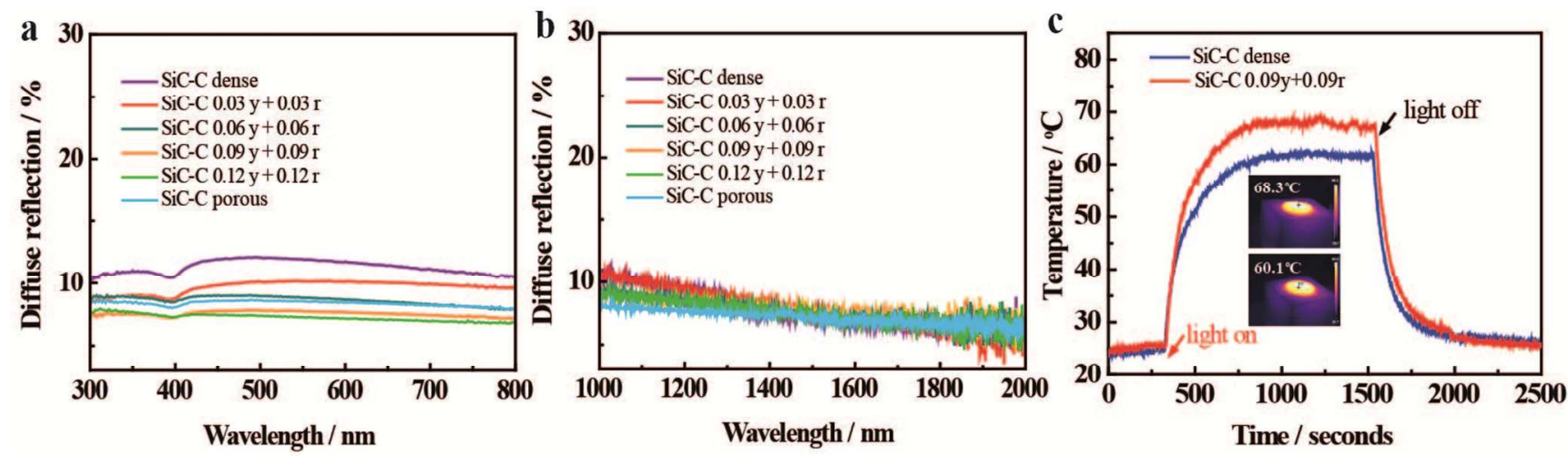

232

233 Figure 4 Diffusion reflectance measurements of SiC-C monoliths in UV-Vis range (a) and in IR range (b). (c)

234 Time-course of the temperature of SiC-C $(0.09 \mathrm{y}+0.09 \mathrm{r})$ monolith and SiC-C dense monolith. Inset images are

235 the steady-state temperature under solar illumination (AM 1.5) of SiC-C $(0.09 \mathrm{y}+0.09 \mathrm{r})$ monolith and SiC-C

236 dense monolith respectively.

237 The UV-Vis-IR reflectance measurement results show that the SiC-C monoliths have a 238 relatively low light diffusion reflection in both UV-Vis spectra (Figure 5a) and IR spectrum 239 (Figure 5b), indicating that the SiC-C monoliths have a good light absorption within almost 240 the entire spectral range of solar irradiation, i.e., from $\sim 300 \mathrm{~nm}$ to $\sim 2.0 \mu \mathrm{m}$. As seen from 241 Figure $4 \mathrm{a}$, the tandem structure shows less diffusion reflection from 300 to $800 \mathrm{~nm}$ than both 242 SiC-C dense monolith and $\mathrm{SiC}-\mathrm{C}$ porous monolith, indicating the role of the rationally 
243 designed tandem structure on the light adsorption enhancement. As can be seen, the diffusion 244 reflection is decreasing as the increasing amounts of the sacrificial templates, which is 245 consistent with the visual color changes of the samples (Figure S2). On the other hand, the 246 difference in the IR absorption by the structural design is not as significant (Figure 4b)

247 Having confirmed the light absorption enhancement of the SiC-C monoliths, their photo248 thermal properties are investigated. Figure 4c presents the materials' surface temperature in 249 air as a function of illumination time under solar simulation of one sun. Upon light 250 illumination, the surface of $\mathrm{SiC}-\mathrm{C}$ monolith rises quickly to a steady-state temperature after 251 around 700 seconds. Inset in Figure 4c is IR images of the SiC-C monolith and SiC-C dense 252 monolith obtained after illumination for 900 s. The IR images of other samples after 253 illumination for $60 \mathrm{~s}$ and $900 \mathrm{~s}$ are presented in Figure S13 and Figure S14. The SiC-C dense 254 monolith has a lower surface temperature of $\sim 60.1{ }^{\circ} \mathrm{C}$ compared to the $\mathrm{SiC}-\mathrm{C}(0.09 \mathrm{y}+0.09 \mathrm{r})$ 255 monolith of $\sim 68.3^{\circ} \mathrm{C}$, which indicates that the tandem-structured SiC-C monolith has a better 256 photo-to-thermal conversion performance and is partially due to the tandem monolith having 257 higher light absorption. Upon light off, both materials have a quick drop in their surface 258 temperatures in response. 

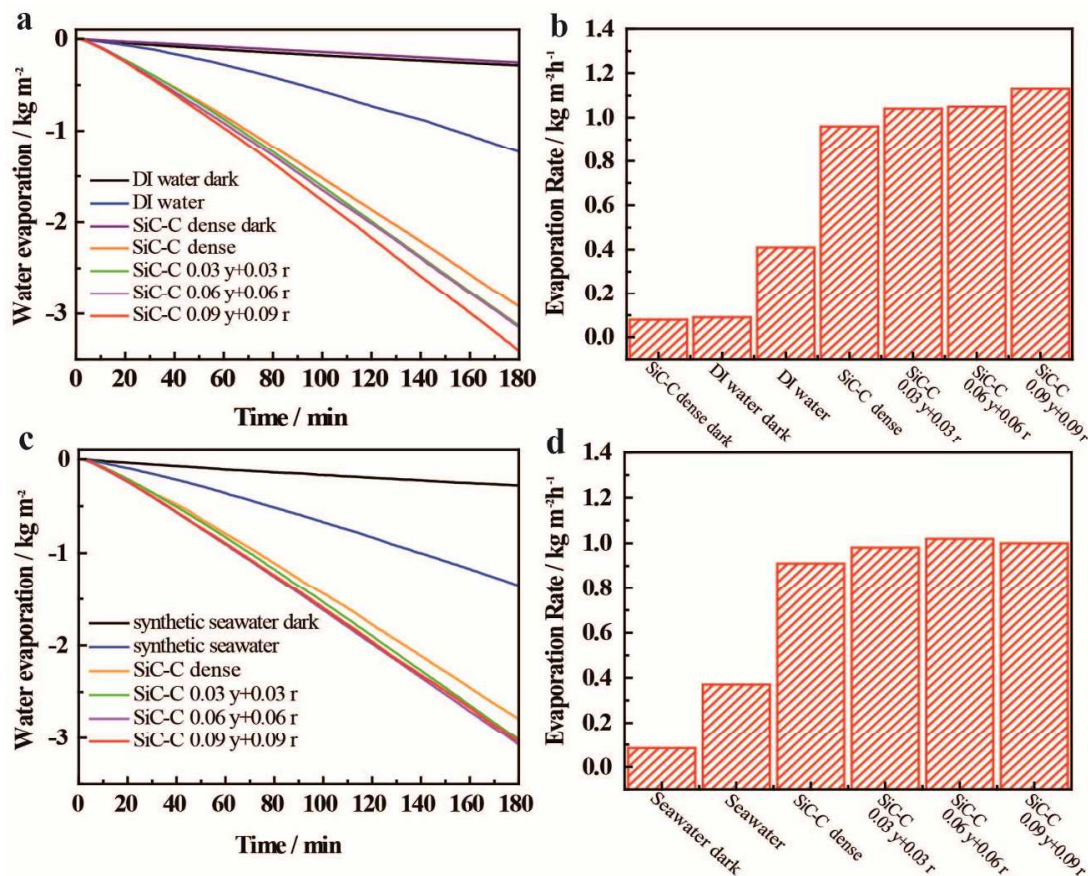

259 Figure 5 Time-course of (a) DI water and (c) 3.5\% NaCl solution evaporation performance by SiC-C monoliths 260 under various conditions. The average (b) DI water and (d) $3.5 \% \mathrm{NaCl}$ solution evaporation rate of final 30 261 minutes.

262 Figure $5 \mathrm{a}$ and $5 \mathrm{~b}$ present the time course of DI water evaporation by SiC-C monoliths with 263 different amount of sacrificial templates under solar irradiation. As can be seen, the amount of 264 water evaporated increases with the increase of the sacrificial templates in the preparation 265 process. All of the tandem-structured $\mathrm{SiC}-\mathrm{C}$ monoliths evaporate more water than $\mathrm{SiC}-\mathrm{C}$ 266 dense monolith. Evaporation of $3.5 \% \mathrm{NaCl}$ solution, a simplified surrogate of seawater, is 267 tested and presented in Figure 5c and 5d. The solar-to-evaporation efficiency $\eta$ of DI water 268 and $3.5 \% \mathrm{NaCl}$ solution evaporation are calculated by following literature method (SI) and 269 Figure S15 and Figure S16 present $\eta$ as a function of illumination time. Generally, SiC-C 270 monoliths all show satisfactory energy efficiency. For example, the $\eta$ of SiC-C $(0.09 \mathrm{y}+0.09 \mathrm{r})$ 271 is $\sim 71 \%$ for DI water and is $\sim 65 \%$ for $3.5 \% \mathrm{NaCl}$ solution, which make them promising for 272 practical applications. 

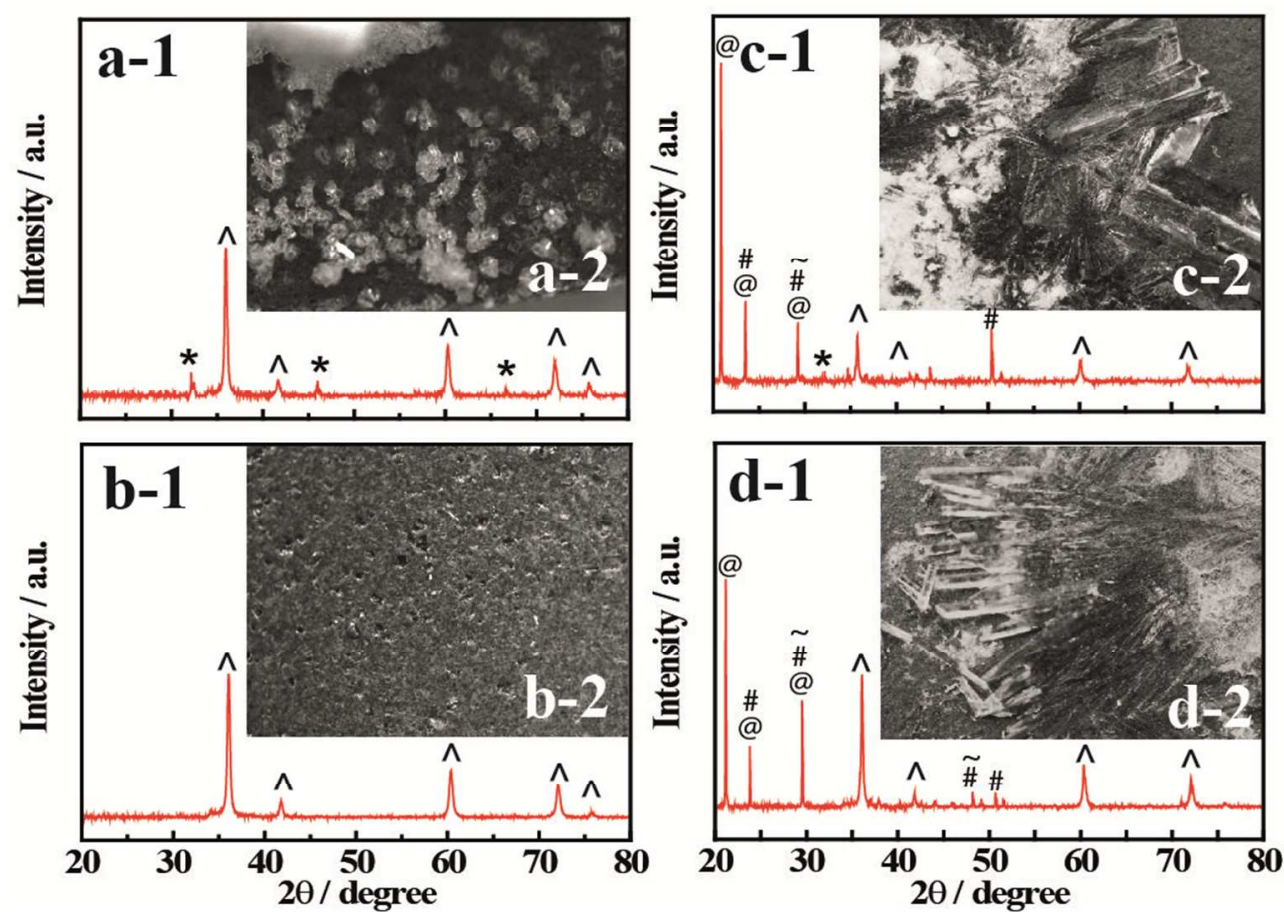

273 Figure 6 XRD spectra of $\mathrm{SiC}-\mathrm{C}(0.09 \mathrm{y}+0.09 \mathrm{r})$ monolith with salts precipitation from $3.5 \% \mathrm{NaCl}$ solution (a) and

274 after water flushing cleaning (b); salts precipitation from commercial synthetic seawater (c) and after water 275 flushing cleaning (d). Insets are microscopic images of top view of each sample. (^ indicates SiC, * indicates

$276 \mathrm{NaCl}, \sim$ indicates $\mathrm{MgCO}_{3}, @$ indicates $\mathrm{CaCO}_{3}$ and \# indicates $\left.\mathrm{CaSO}_{4}\right)$

277 There is clearly a layer of solid precipitates on the surface of the SiC-C monolith after $3.5 \%$

$278 \mathrm{NaCl}$ solution evaporation for 3 hours (Figure $\mathrm{S} 17 \mathrm{a}$ ), which is further confirmed by 279 microscopic images (Figure 6a-2). The XRD spectra (Figure 6a-1) determine that the salt 280 crystals are only $\mathrm{NaCl}$. Simple flowing water flushing is applied to clean the surface salt off 281 the material. It turns out that the surface salts can be easily removed this way (Video 1). The 282 SiC-C monolith after the water flushing shows a visually clear surface (Figure S17b). The 283 XRD spectra (Figure 6b-1) and microscopic image (Figure 6b-2) further confirm that all the 284 peaks from $\mathrm{NaCl}$ disappear after the cleaning. The results of easy $\mathrm{NaCl}$ removal are consistent 285 with the literature reports. ${ }^{44}$ Later on, water evaporation test was conducted by using 286 commercial synthetic seawater whose ion composition is shown in Table S1. The SiC-C 
287 monoliths after the commercial synthetic seawater evaporation were further investigated by $288 \mathrm{XRD}$ who results show that the salt crystals on the $\mathrm{SiC}-\mathrm{C}$ surface were $\mathrm{NaCl}, \mathrm{MgCO}_{3}, \mathrm{CaCO}_{3}$ 289 and $\mathrm{CaSO}_{4}$ (Figure 6c-1). After water flushing cleaning, highly soluble salt precipitate, such 290 as $\mathrm{NaCl}$, was removed, suggesting that the less soluble salts on the surface of material are 291 potential scaling species.
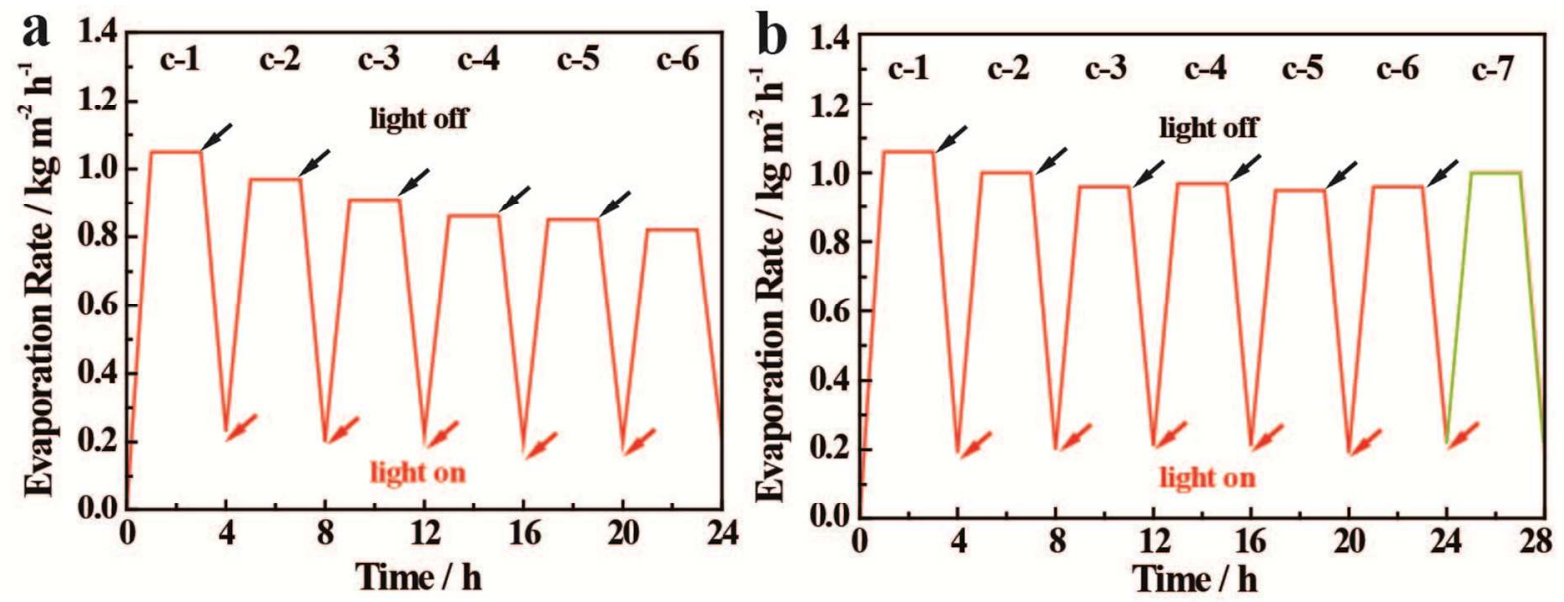

293 Figure 7 Water evaporation performance of Red Sea water by the SiC-C $(0.09 \mathrm{y}+0.09 \mathrm{r})$ monolith. (a) Water 294 evaporation rate as a function of evaporation time lasting for 6 cycles (c-1 to c-6). In each cycle, light is on for 3 295 hours and light is off for 1 hour. (b) Water evaporation rate as a function of evaporation time for 7 cycles, with 296 water flushing and brush scrubbing at the end of each cycle of the first 6 to clean surface foulants and with 297 additional sonication before the $7^{\text {th }}$ cycle.

298 The natural Red Sea water is then sampled and used for the water evaporation test under the 299 otherwise same conditions and different results are observed. In order to investigate the effect 300 of the fouling layers on the water evaporation performance over long-term operation, cycle 301 stability is investigated and the water evaporation performance is tested for 6 cycles with each 302 cycle consisting of a light-on step for 3 hours and a light-off step for 1 hour. 
303 Figure 7a presents the water evaporation rate as a function of evaporation time for 6 cycles 304 without any surface foulant cleaning. The water evaporation rate decreases from $1.05 \mathrm{~kg} \mathrm{~m}^{-2}$ $305 \mathrm{~h}^{-1}$ in the first cycle to $0.82 \mathrm{~kg} \mathrm{~m}^{-2} \mathrm{~h}^{-1}$ in the sixth cycle, representing a $21.9 \%$ performance 306 decline. Figure S18a presents digital photos of the material surface after each cycle and 307 clearly show thick fouling layers on the surface of the SiC-C $(0.09 y+0.09 r)$ monolith. The 308 presence of the fouling layers and more importantly significantly reduced performance 309 warrants certain foulant cleaning methods to be taken on the materials. In this case, water 310 flushing and brush-scrubbing are taken to clean the foulants off the materials (Figure S18b-1 311 to b-4, Video 2 and Video 3).

312 Figure $7 \mathrm{~b}$ presents the water evaporation rates as a function of evaporation time for 6 cycles, 313 with the foulant cleaning via water flushing and brushing after each cycle. The water 314 evaporation rate decreases in this case from $1.06 \mathrm{~kg} \mathrm{~m}^{-2} \mathrm{~h}^{-1}$ in the first cycle to $0.96 \mathrm{~kg} \mathrm{~m}^{-2} \mathrm{~h}^{-1}$ 315 in the sixth cycle, showing a much less $9.4 \%$ decline compared with the $21.9 \%$ decline in the 316 case without any foulant cleaning. Figure S19 presents the microscopic images of Si-C 317 monolith with fouling layer, after cleaning with water flushing and after cleaning with 318 brushing. The obvious difference between the two cases indicates the importance of periodical 319 physical cleaning of the photothermal material in order to keep a relatively stable performance.

320 Then the same SiC-C monolith is further cleaned by sonication in DI water for 30 min (Video 3214 ), and the evaporation performance is presented in Figure 7b cycle-7, where the evaporation 322 rate is recovered to $94.3 \%$ of the evaporation rate in first cycle. It is worth emphasizing that the 323 sonication water container does not show any significant color change before and after 324 sonication the $\mathrm{SiC}-\mathrm{C}$ monolith in it (Figure S18c-1 and c-2), implying there are not carbon 325 particles coming out of the $\mathrm{SiC}-\mathrm{C}$ monolith and into the water. The anti-carbon-loss 
326 mechanism in the SiC-C monolith effectively locks the photothermal carbon into the matrix of

$327 \mathrm{SiC}$ securely. It has to be pointed out that most of the previous photothermal materials in the

328 literature cannot withstand water flushing or sonication treatment for an extended time without

329 losing their structural integrity or losing their photothermal components (Figure S20). ${ }^{45}$ More

330 tests have been done to investigate the mechanical property of SiC-C monolith by a simple 331 pressure test (Figure S21), whose results show that a SiC-C $(0.09 y+0.09 r)$ monolith sample 332 (with diameter of $39.3 \mathrm{~mm}$ and thickness of $1.1 \mathrm{~mm}$ ) can hold a relative high pressure as high 333 as $0.84 \times 10^{6} \mathrm{~Pa}$.
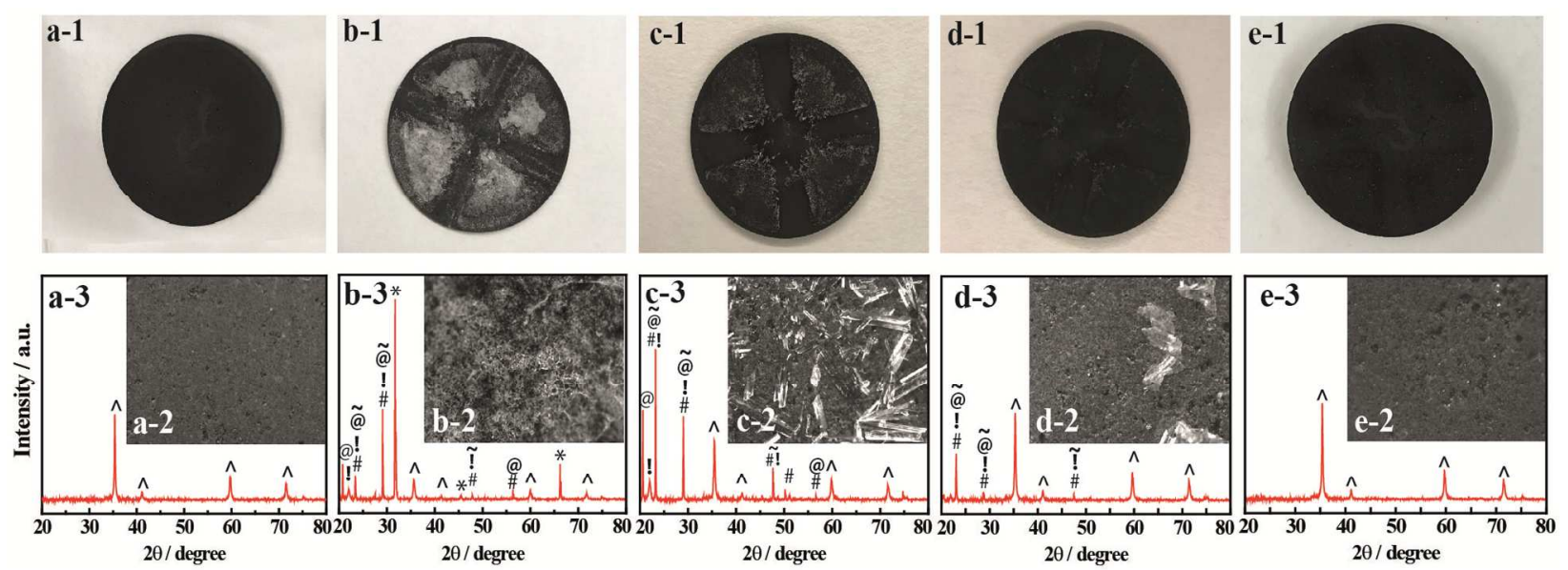

Figure 8 Top view of digital photos and microscopic pictures of SiC-C $(0.09 y+0.09 r)$ composite monolith under different conditions in Red Sea water for water evaporation: the freshly prepared SiC-C $(0.09 \mathrm{y}+0.09 \mathrm{r})$ monolith (a-1 and a-2), the SiC-C (0.09y+0.09r) monolith with fouling layer after water evaporation for 6 cycles (b-1 and b-2), the fouling layers after cleaning with water flushing (c-1 and c-2), after cleaning by brush scrubbing (d-1 and d-2), and after cleaning with sonication for $30 \mathrm{~min}$ (e-1 and e-2). a3-e3 present the XRD spectra of each sample. $\left(\wedge\right.$ indicates $\mathrm{SiC}, *$ indicates $\mathrm{NaCl}, \sim$ indicates $\mathrm{MgCO}_{3}$, @ indicates $\mathrm{CaCO}_{3}$, \# indicates $\mathrm{CaSO}_{4}$, and ? indicates $\mathrm{SiO}_{2}$ (Cristobalite)). 
342 To ascertain the fouling species and their remvoal during the above experiments, more 343 detailed surface morphologies and XRD based speciation analysis are conducted. Figure 8 344 presents the digital photos and top view microscopic pictures of $\mathrm{SiC}-\mathrm{C}(0.09 \mathrm{y}+0.09 \mathrm{r})$ 345 monolith under different conditions: monolith freshly prepared (Figure 8a), monolith with 346 fouling layer after water evaporation with Red Sea water for 6 cycles (Figure 8b), monolith 347 after cleaning by flushing DI water (Figure 8c), monolith after cleaning with brush scrubbing 348 (Figure 8d), and monolith after cleaning with sonication for 30 min (Figure 8e). From Figure $3498 b-2$, there is a severe surface fouling of SiC-C $(0.09 y+0.09 r)$ monolith after 6 cycles of Red 350 Sea water evaporation. The XRD analysis reveals that the fouling species are crystals of $\mathrm{NaCl}$, $351 \mathrm{MgCO}_{3}, \mathrm{CaCO}_{3}$ and $\mathrm{CaSO}_{4}$ (Figure 8b-3), which is in agreement with the ion composition of 352 Red Sea water (Table S2). A peak from $\mathrm{SiO}_{2}$ (Cristobalite) was found interestingly at around $35322^{\circ}$, which is different from the commercial seawater. Simple flowing water flushing, the 354 same as the previous $3.5 \% \mathrm{NaCl}$ solution case, is applied to clean the material (Video 2) and 355 after which there are still a lot of solid residues left on the surface of the monolith (Figure 8c3561 and $\mathrm{c}-2$ ). However, the XRD results show that the simple water flushing successfully 357 removes $\mathrm{NaCl}$ out of the material as the peaks from crystals of $\mathrm{NaCl}$ disappears entirely after 358 the flushing (Figure 8c-3). Apparently, these leftover fouling species after the simple flushing 359 are these carbonate and sulfate species, which cannot be removed from the materials by the 360 simple water flushing probably due to their low water solubility.

361 Strong brush scrubbing is applied to clean the material surface under flowing tap water 362 (Video 3), after which the peaks from $\mathrm{MgCO}_{3}, \mathrm{CaCO}_{3}$ and $\mathrm{CaSO}_{4}$ are reduced significantly 363 (Figure 8d-3) and the material surface looks much cleaner (Figure 8d-1). However, this step 364 still does not remove these sulfate species completely as shown in XRD pattern as well as in 
365 Figure 8d-2. In order to further clean the SiC-C monolith, the sample is sonicated while 366 immersed in DI water for 30 min (Video 4). After the sonication, there are not any visible 367 residues on the surface of the $\mathrm{SiC}-\mathrm{C}$ monolith (Figure $8 \mathrm{e}-1$ and $8 \mathrm{e}-2$ ). As matter of fact, the 368 sonication successful removes all inorganic fouling species, leaving behind only peaks for SiC 369 monolith (Figure 8e-3) and meaning that the SiC-C monolith is completely regenerated.

370 First, our results clearly demonstrate that fouling will be a very serious issue for the practical 371 solar-driven water evaporation applications where natural and typically dirty water is involved. 372 Thus having regenerable property is very much needed for the photothermal designs intended 373 for these applications. Secondly, it is the first time that the difference in fouling behaviors of 374 solar-driven evaporation of the natural seawater (Red Sea water) and $3.5 \% \mathrm{NaCl}$ solution is 375 reported. While surface $\mathrm{NaCl}$ salt precipitate on the photothermal material can be easily 376 removed by simple water flushing, the carbonate and sulfate species of $\mathrm{MgCO}_{3}, \mathrm{CaCO}_{3}$, $377 \mathrm{CaSO}_{4}$, etc. are difficult to remove once they precipitate on the surface of photothermal 378 materials. For example, the solubility of $\mathrm{CaSO}_{4}$ increases with increasing $\mathrm{NaCl}$ concentration, 379 which explains the fact that there is dissolved $\mathrm{CaSO}_{4}$ in natural seawater and also the fact that 380 once it is precipitated it would be difficult to remove by simple water flushing given its small 381 water solubility in water. ${ }^{46}$ The carbonate species, such as $\mathrm{CaCO}_{3}$, whose solubility decreases 382 with increasing temperature, is one of the main species for scaling. ${ }^{47-48}$ The term fouling is 383 used in the manuscript indiscriminately thereafter to describe the problem caused by salt 384 scaling and organic species induced fouling.

385 Most of the previous photothermal works investigating seawater evaporation oversimplify 386 their experimental conditions by using $3.5 \% \mathrm{NaCl}$ solution. The fouling scenarios of $3.5 \%$ $387 \mathrm{NaCl}$ solution and natural seawater can be drastically different. The scaling potential can also 
388 be confirmed by calculation of Langelier Saturation Index (LSI), which indicates the driving 389 force for scale formation depending on factors such as water $\mathrm{pH}$, the saturation $\mathrm{pH}(\mathrm{pHs})$, 390 temperature, salinity, calcium hardness and alkalinity of water. ${ }^{49}$ The details of LSI 391 calculation can be found in supporting information. The calculated LSI is 0.38 , which means 392 that the tested seawater from Red Sea is supersaturated with respect to calcium carbonate and 393 there is a high potential for scaling occurring. As for the solar-driven water evaporation 394 system, the concentration of salts on the surface of photothermal material is increasing 395 monotonically during the process of water evaporation. In addition, LSI is temperature 396 sensitive, which means LSI becomes more positive as the water temperature increases. In 397 other words, solar-driven water evaporation by photothermal material may intensify the water 398 supersaturating condition and thus have serious scaling concern. For the natural seawater 399 solar-driven evaporation, the photothermal material design, in addition to light absorption, 400 heat conversion, and heat concentration requirements, ought to have another requirement of 401 mechanical strength and stability so the material can survive envisioned fouling control 402 measures, including cascading means of water flushing, surface brushing, and sonication to 403 have inorganic species in fouling layer removed. In this regard, the $\mathrm{SiC}-\mathrm{C}$ monolith in this 404 work provides a good example of a sturdy and effective photothermal materials towards 405 durable real world application of solar-driven water evaporation. 

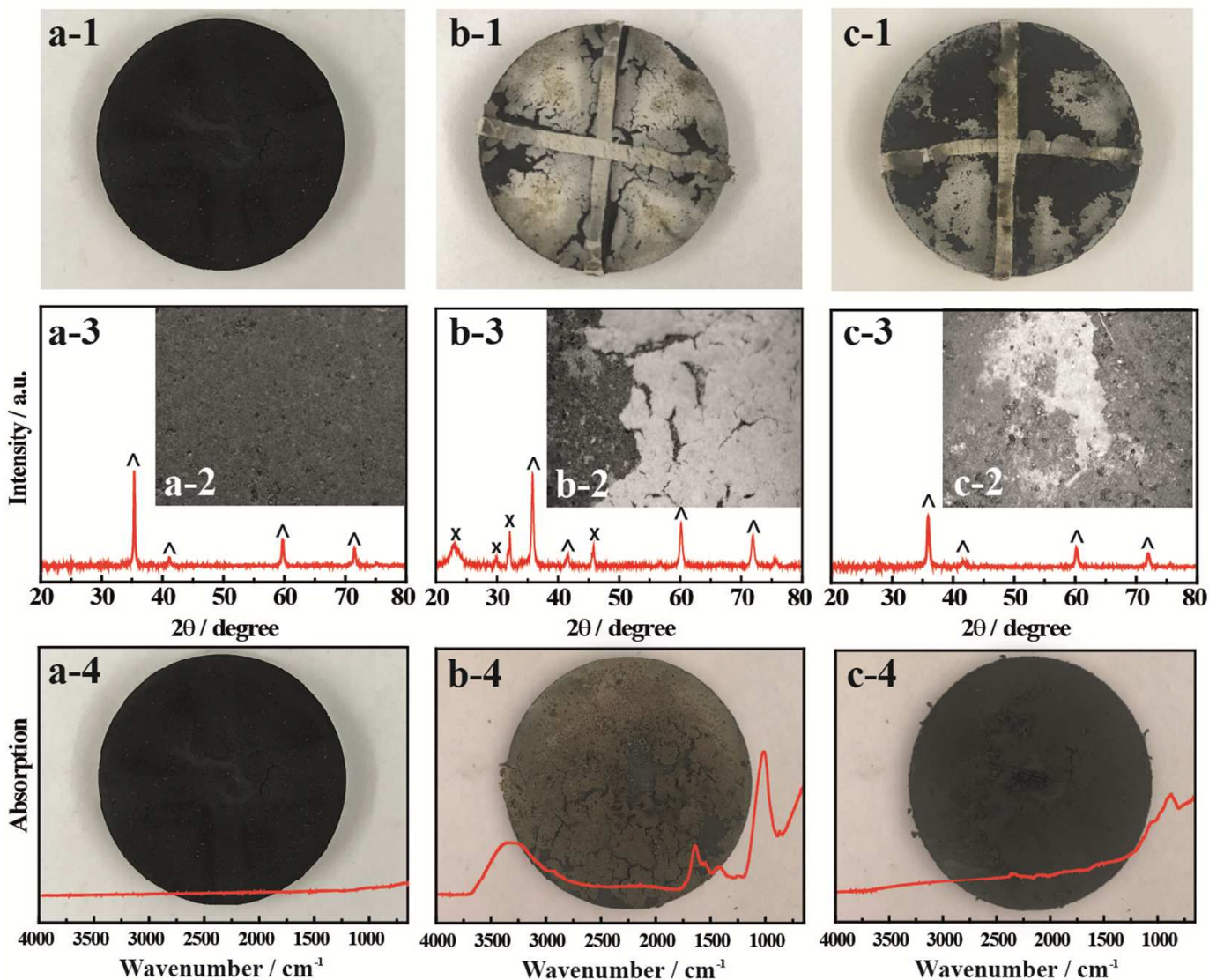

Figure 9 Top view digital photos and microscopic pictures of SiC-C $(0.09 \mathrm{y}+0.09 \mathrm{r})$ monolith under different conditions with domestic wastewater (treated after screen, collected from WWTP at KAUST): (a-1 and a-2) the

409 freshly prepared SiC-C $(0.09 \mathrm{y}+0.09 \mathrm{r})$ monolith, (b-1 and b-2) the SiC-C $(0.09 \mathrm{y}+0.09 \mathrm{r})$ monolith with fouling

410 layers after water evaporation in wastewater and (c-1 and c-2) the SiC-C monolith with fouling layers after

411 cleaning with water flushing and brushing. a2-c2 present the microscopic images of each sample (5X). a3-c3

412 present the XRD spectra of each sample. (^ indicates $\mathrm{SiC}, \mathrm{X}$ indicates unnoted species in wastewater). Curve in 413 a-4, b-4 and c-4 present the FTIR results of each sample under different condition: freshly prepared SiC-C $414(0.09 y+0.09 r)$ monolith (a-4), with fouling layer from wastewater evaporation (b-4) and with fouling layer from 415 wastewater evaporation after annealing treatment at $1000{ }^{\circ} \mathrm{C}$ in $\mathrm{N}_{2}(\mathrm{c}-4)$.

416 Furthermore, the $\mathrm{SiC}-\mathrm{C}$ monolith is challenged by solar-driven domestic wastewater 417 evaporation. The domestic wastewater sample right after physical screening was collected 418 from WWTP at KAUST, Saudi Arabia. In addition, the water quality test of each water 419 sample is presented in Table S3 in SI. As expected, a thick fouling layer is observed on the 
420 surface of the SiC-C monolith after wastewater evaporation and the XRD analysis reveals 421 some unknown species on the material surface (Figure 9b).

422 For the fouling layer coming from the domestic wastewater, simple flowing water flushing is 423 ineffective (Figure 9c-1 and 9c-3, Video 5). The main fouling species in this case are organic 424 substances as indicated by FTIR spectrum (Figure 9b-4). The FTIR spectra show the 425 dominant functional groups in the fouling layer are amides with absorbance peaks at 3319, 4261629,1541 and $1412 \mathrm{~cm}^{-1} .^{50}$ The peak at $2934 \mathrm{~cm}^{-1}$ indicates the C-H bond of alkyl. The peak 427 observed at $1238 \mathrm{~cm}^{-1}$ could be due to the presence of $-\mathrm{CH}_{3}$ and $\mathrm{C}-\mathrm{H}$ bond in methyl group. ${ }^{51}$ 428 A sharp peak at $1020-1070 \mathrm{~cm}^{-1}$ exhibits the character of carbohydrates or carbohydrates-like 429 substances. ${ }^{52}$ A freshly fouled SiC-C monolith after the wastewater evaporation is annealed at $4301000{ }^{\circ} \mathrm{C}$ in $\mathrm{N}_{2}$ atmosphere and Figure 9c-4 shows a photo of the fouled SiC-C monolith after 431 annealing treatment. On the one hand, the decrease in the number of FTIR peaks is observed, 432 which means that annealing treatment successfully mineralizes most of the organic 433 compounds in the fouling layer. ${ }^{53}$ On the other hand, the $\mathrm{SiC}-\mathrm{C}$ monolith preserves 434 compositional and structural integrity due to its excellent thermal stability.

\section{CONCLUSIONS}

437 This work draws attention onto the fouling issue during practical applications of solar-driven 438 water evaporation of real seawater and wastewater. At the same time, this work demonstrates 439 that the tandem-structured SiC-C monolith, consisting of a top porous layer and a bottom 440 dense layer, is a promising photothermal material towards practical applications. The material 441 has satisfactory solar-to-evaporation performance and more importantly high mechanical 
442 strength and durability. These properties make the material able to withstand essential fouling 443 control approaches, water flushing, brush scrubbing and sonication, which none of the 444 previous photothermal materials is able to. Moreover, the high thermal stability of the 445 material allows for $1000^{\circ} \mathrm{C}$ heat treatment to remove organic foulants. This study shines light 446 on the potential use of ceramic-based materials as photothermal materials in practical solar447 driven seawater desalination and wastewater treatment.

449 ASSOCIATED CONTENT

450 Supporting Information. This material is available free of charge via the Internet at 451 http://pubs.acs.org.

452 Schematic image of synthesis process of SiC-C monolith; digital photos, SEM and 453 microscopic images of precursors, SiC-C monolith samples and fouled surface of SiC-C 454 samples; XRD for SiC-C monolith samples and precursors under different conditions; Raman 455 for SiC precursors; digital photos for chemical stability test; IR images for SiC-C monolith 456 samples under illumination for 60s and 900s; equations for water evaporation rate and solar to 457 evaporation efficiency calculation; the average evaporation efficiency for DI water and 3.5\% $458 \mathrm{NaCl}$ solution under different conditions; digital photos of $\mathrm{SiC}-\mathrm{C}$ monolith with salts 459 precipitation after 3.5\% $\mathrm{NaCl}$ solution and commercial synthetic seawater evaporation; digital 460 photos of SiC-C monolith during evaporation process and cleaning process; comparison of 461 mechanical stability with other materials; digital photos showing pressure test process; table 462 of ion composition of the commercial synthetic seawater, the sample of Red Sea water and 463 water quality of different water samples; calculation of Langelier Saturation Index (LSI). 
464

465

466

467

468

469

470

471

472

473

474

475

476

477

478

479

480

481

482

483

484

485

486

487

488

489

490

491

492

493

494

495

496

497

498

499

\section{ACKNOWLEDGMENTS}

This project is based upon work supported by the King Abdullah University Science and

Technology (KAUST) CCF fund awarded to Water Desalination and Reuse Center (WDRC).

Le Shi would like to thank Ran Tao from Mechanical Engineering at KAUST for his suggestions and comments of mechanical properties characterization.

\section{REFERENCES}

1. Politano, A.; Argurio, P.; Di Profio, G.; Sanna, V.; Cupolillo, A.; Chakraborty, S.; Arafat, H. A.; Curcio, E., Photothermal Membrane Distillation for Seawater Desalination. Advanced Materials 2017, 29 (2), 1603504-n/a.

2. Fane, A. G.; Wang, R.; Hu, M. X., Synthetic Membranes for Water Purification: Status and Future. Angewandte Chemie International Edition 2015, 54 (11), 3368-3386.

3. Chu, S.; Majumdar, A., Opportunities and challenges for a sustainable energy future. Nature 2012, 488, 294.

4. Wang, Y.; Zhang, L.; Wang, P., Self-Floating Carbon Nanotube Membrane on Macroporous Silica Substrate for Highly Efficient Solar-Driven Interfacial Water Evaporation. ACS Sustainable Chemistry \& Engineering 2016, 4 (3), 1223-1230.

5. Xue, G.; Liu, K.; Chen, Q.; Yang, P.; Li, J.; Ding, T.; Duan, J.; Qi, B.; Zhou, J., Robust and LowCost Flame-Treated Wood for High-Performance Solar Steam Generation. ACS Applied Materials \& Interfaces 2017, 9 (17), 15052-15057.

6. Ghasemi, H.; Ni, G.; Marconnet, A. M.; Loomis, J.; Yerci, S.; Miljkovic, N.; Chen, G., Solar steam generation by heat localization. Nature Communications 2014, 5, 4449.

7. Li, X.; Xu, W.; Tang, M.; Zhou, L.; Zhu, B.; Zhu, S.; Zhu, J., Graphene oxide-based efficient and scalable solar desalination under one sun with a confined 2D water path. Proceedings of the National Academy of Sciences 2016, 113 (49), 13953-13958.

8. Shi, L.; Wang, Y.; Zhang, L.; Wang, P., Rational design of a bi-layered reduced graphene oxide film on polystyrene foam for solar-driven interfacial water evaporation. Journal of Materials Chemistry A 2017, 5 (31), 16212-16219.

9. Zhou, L.; Tan, Y.; Wang, J.; Xu, W.; Yuan, Y.; Cai, W.; Zhu, S.; Zhu, J., 3D self-assembly of aluminium nanoparticles for plasmon-enhanced solar desalination. Nat Photon 2016, 10 (6), 393-398. 10. Wang, Z.; Liu, Y.; Tao, P.; Shen, Q.; Yi, N.; Zhang, F.; Liu, Q.; Song, C.; Zhang, D.; Shang, W.; Deng, T., Bio-Inspired Evaporation Through Plasmonic Film of Nanoparticles at the Air-Water Interface. Small 2014, 10 (16), 3234-3239.

11. Liu, Y.; Yu, S.; Feng, R.; Bernard, A.; Liu, Y.; Zhang, Y.; Duan, H.; Shang, W.; Tao, P.; Song, C.; Deng, T., A Bioinspired, Reusable, Paper-Based System for High-Performance Large-Scale Evaporation. Advanced Materials 2015, 27 (17), 2768-2774. 
500 12. Bae, K.; Kang, G.; Cho, S. K.; Park, W.; Kim, K.; Padilla, W. J., Flexible thin-film black gold 501 membranes with ultrabroadband plasmonic nanofocusing for efficient solar vapour generation. 502 Nature Communications 2015, 6, 10103.

503 13. Zhang, L.; Tang, B.; Wu, J.; Li, R.; Wang, P., Hydrophobic Light-to-Heat Conversion 504 Membranes with Self-Healing Ability for Interfacial Solar Heating. Advanced Materials 2015, 27 (33), 505 4889-4894.

506 14. Li, R.; Zhang, L.; Shi, L.; Wang, P., MXene Ti3C2: An Effective 2D Light-to-Heat Conversion 507 Material. ACS Nano 2017, 11 (4), 3752-3759.

508 15. Zhu, G.; Xu, J.; Zhao, W.; Huang, F., Constructing Black Titania with Unique Nanocage 509 Structure for Solar Desalination. ACS Applied Materials \& Interfaces 2016, 8 (46), 31716-31721.

$510 \quad$ 16. $\quad$ Wang, J.; Li, Y.; Deng, L.; Wei, N.; Weng, Y.; Dong, S.; Qi, D.; Qiu, J.; Chen, X.; Wu, T., High511 Performance Photothermal Conversion of Narrow-Bandgap Ti2O3 Nanoparticles. Advanced Materials 512 2017, 29 (3), 1603730-n/a.

513 17. Rathinam, K.; Oren, Y.; Petry, W.; Schwahn, D.; Kasher, R., Calcium phosphate scaling during 514 wastewater desalination on oligoamide surfaces mimicking reverse osmosis and nanofiltration 515 membranes. Water Research 2018, 128 (Supplement C), 217-225.

$516 \quad$ 18. He, Z.; Kasemset, S.; Kirschner, A. Y.; Cheng, Y.-H.; Paul, D. R.; Freeman, B. D., The effects of 517 salt concentration and foulant surface charge on hydrocarbon fouling of a poly(vinylidene fluoride) 518 microfiltration membrane. Water Research 2017, 117 (Supplement C), 230-241.

519 19. Zhang, M.; Hong, H.; Lin, H.; Shen, L.; Yu, H.; Ma, G.; Chen, J.; Liao, B.-Q., Mechanistic insights 520 into alginate fouling caused by calcium ions based on terahertz time-domain spectra analyses and 521 DFT calculations. Water Research 2017.

522 20. Shan, L.; Fan, H.; Guo, H.; Ji, S.; Zhang, G., Natural organic matter fouling behaviors on 523 superwetting nanofiltration membranes. Water Research 2016, 93 (Supplement C), 121-132.

524 21. Han, G.; Zhou, J.; Wan, C.; Yang, T.; Chung, T.-S., Investigations of inorganic and organic 525 fouling behaviors, antifouling and cleaning strategies for pressure retarded osmosis (PRO) membrane 526 using seawater desalination brine and wastewater. Water Research 2016, 103 (Supplement C), 264527275.

528 22. Chen, J. P.; Kim, S. L.; Ting, Y. P., Optimization of membrane physical and chemical cleaning 529 by a statistically designed approach. Journal of Membrane Science 2003, 219 (1), 27-45.

530 23. Weerasekara, N. A.; Choo, K.-H.; Lee, C.-H., Hybridization of physical cleaning and quorum 531 quenching to minimize membrane biofouling and energy consumption in a membrane bioreactor. 532 Water Research 2014, 67 (Supplement C), 1-10.

533 24. Lee, S.; Elimelech, M., Salt cleaning of organic-fouled reverse osmosis membranes. Water 534 Research 2007, 41 (5), 1134-1142.

535 25. Siembida, B.; Cornel, P.; Krause, S.; Zimmermann, B., Effect of mechanical cleaning with 536 granular material on the permeability of submerged membranes in the MBR process. Water Research 537 2010, $44(14), 4037-4046$.

538 26. Yu, S.; Zhang, Y.; Duan, H.; Liu, Y.; Quan, X.; Tao, P.; Shang, W.; Wu, J.; Song, C.; Deng, T., The 539 impact of surface chemistry on the performance of localized solar-driven evaporation system. 540 Scientific Reports 2015, 5, 13600.

541 27. Kozo Ishizaki, S. K., Makoto Nanko, Porous Materials: Process technology and applications. 542 Kluwer Academic Publishers, Dordrecht, The Netherlands (1998) 1998.

543 28. Chi, W.; Jiang, D.; Huang, Z.; Tan, S., Sintering behavior of porous SiC ceramics. Ceramics $544 \quad$ International 2004, 30 (6), 869-874.

545 29. Lanfant, B.; Leconte, Y.; Bonnefont, G.; Garnier, V.; Jorand, Y.; Le Gallet, S.; Pinault, M.; 546 Herlin-Boime, N.; Bernard, F.; Fantozzi, G., Effects of carbon and oxygen on the spark plasma 
sintering additive-free densification and on the mechanical properties of nanostructured SiC ceramics. Journal of the European Ceramic Society 2015, 35 (13), 3369-3379. 30. Eom, J.-H.; Kim, Y.-W.; Raju, S., Processing and properties of macroporous silicon carbide ceramics: A review. Journal of Asian Ceramic Societies 2013, 1 (3), 220-242.

551 31. Rączka, M.; Górny, G.; Stobierski, L.; Rożniatowski, K., Effect of carbon content on the 552 microstructure and properties of silicon carbide-based sinters. Materials Characterization 2001, 46 553 (2), 245-249.

554 32. Lewis, J. A.; Cima, M. J.; Rhine, W. E., Direct Observation of Preceramic and Organic Binder 555 Decomposition in 2-D Model Microstructures. Journal of the American Ceramic Society 1994, 77 (7), 556 1839-1845.

557 33. Shi, Y. F.; Meng, Y.; Chen, D. H.; Cheng, S. J.; Chen, P.; Yang, H. F.; Wan, Y.; Zhao, D. Y., Highly 558 Ordered Mesoporous Silicon Carbide Ceramics with Large Surface Areas and High Stability. Advanced 559 Functional Materials 2006, 16 (4), 561-567.

$560 \quad 34 . \quad$ Krawiec, P.; Schrage, C.; Kockrick, E.; Kaskel, S., Tubular and Rodlike Ordered Mesoporous 561 Silicon (Oxy)carbide Ceramics and their Structural Transformations. Chemistry of Materials 2008, 20 562 (16), 5421-5433.

$563 \quad 35 . \quad$ Nghiem, Q. D.; Kim, D.-P., Direct Preparation of High Surface Area Mesoporous SiC-Based 564 Ceramic by Pyrolysis of a Self-Assembled Polycarbosilane-block-Polystyrene Diblock Copolymer. 565 566 567 568 Chemistry of Materials 2008, 20 (11), 3735-3739.

36. Lee, H.-W.; Sacks, M. D., Pressureless Sintering of SiC-Whisker-Reinforced Al2O3 Composites: II, Effects of Sintering Additives and Green Body Infiltration. Journal of the American Ceramic Society 1990, 73 (7), 1894-1900.

37. Riedel, R.; Passing, G.; Schönfelder, H.; Brook, R. J., Synthesis of dense silicon-based ceramics at low temperatures. Nature 1992, 355, 714.

38. Kim, Y.-W.; Jin, Y.-J.; Eom, J.-H.; Song, I.-H.; Kim, H.-D., Engineering porosity in silicon carbide ceramics. Journal of Materials Science 2010, 45 (10), 2808-2815.

39. Kim, T. K.; VanSaders, B.; Caldwell, E.; Shin, S.; Liu, Z.; Jin, S.; Chen, R., Copper-alloyed spinel black oxides and tandem-structured solar absorbing layers for high-temperature concentrating solar power systems. Solar Energy 2016, 132 (Supplement C), 257-266.

40. Raut, H. K.; Ganesh, V. A.; Nair, A. S.; Ramakrishna, S., Anti-reflective coatings: A critical, indepth review. Energy \& Environmental Science 2011, 4 (10), 3779-3804.

41. Madaeni, S. S.; Samieirad, S., Chemical cleaning of reverse osmosis membrane fouled by wastewater. Desalination 2010, 257 (1), 80-86.

42. Moene, R.; Makkee, M.; Moulijn, J. A., High surface area silicon carbide as catalyst support characterization and stability. Applied Catalysis A: General 1998, 167 (2), 321-330.

43. Zwinkels, M. F. M.; JÄRÅS, S. G.; Menon, P. G.; Griffin, T. A., Catalytic Materials for HighTemperature Combustion. Catalysis Reviews 1993, 35 (3), 319-358.

44. Finnerty, C.; Zhang, L.; Sedlak, D. L.; Nelson, K. L.; Mi, B., Synthetic Graphene Oxide Leaf for Solar Desalination with Zero Liquid Discharge. Environmental Science \& Technology 2017, 51 (20), 11701-11709.

45. Hu, X.; Xu, W.; Zhou, L.; Tan, Y.; Wang, Y.; Zhu, S.; Zhu, J., Tailoring Graphene Oxide-Based Aerogels for Efficient Solar Steam Generation under One Sun. Advanced Materials 2017, 29 (5), 1604031-n/a.

$590 \quad$ 46. Zhang, Y.; Yang, Z.; Guo, D.; Geng, H.; Dong, C., Effect of Chloride Salts and Bicarbonate on 591 Solubility of $\mathrm{CaSO} 4$ in Aqueous Solutions at $37^{\circ} \mathrm{C}$. Procedia Environmental Sciences 2013, 18 592 (Supplement C), 84-91. 
593 47. Antony, A.; Low, J. H.; Gray, S.; Childress, A. E.; Le-Clech, P.; Leslie, G., Scale formation and 594 control in high pressure membrane water treatment systems: A review. Journal of Membrane Science $5952011,383(1), 1-16$.

596 48. Waly, T.; Kennedy, M. D.; Witkamp, G. J.; Amy, G.; Schippers, J. C., Will calcium carbonate 597 really scale in seawater reverse osmosis? Desalination and Water Treatment 2009, 5 (1-3), 146-152.

598 49. Langelier, W. F., The analytical control of anti-corrosion water treatment. Journal of 599 American Water Works Association 1936, 28, 1500.

600 50. Juntawang, C.; Rongsayamanont, C.; Khan, E., Fouling characterization in entrapped cells601 based-membrane bioreactor treating wastewater. Separation and Purification Technology 2017, 175, 602 321-329.

603 51. Maruyama, T.; Katoh, S.; Nakajima, M.; Nabetani, H.; Abbott, T. P.; Shono, A.; Satoh, K., FT-IR 604 analysis of BSA fouled on ultrafiltration and microfiltration membranes. Journal of Membrane Science 605 2001, $192(1), 201-207$.

606 52. Croué, J. P.; Benedetti, M. F.; Violleau, D.; Leenheer, J. A., Characterization and Copper 607 Binding of Humic and Nonhumic Organic Matter Isolated from the South Platte River: Evidence for 608 the Presence of Nitrogenous Binding Site. Environmental Science \& Technology 2003, 37 (2), 328-336. 609 53. Buthiyappan, A.; Abdul Raman, A. A.; Daud, W. M. A. W., Development of an advanced 610 chemical oxidation wastewater treatment system for the batik industry in Malaysia. RSC Advances 611 2016, 6 (30), 25222-25241. 


\section{TOC}

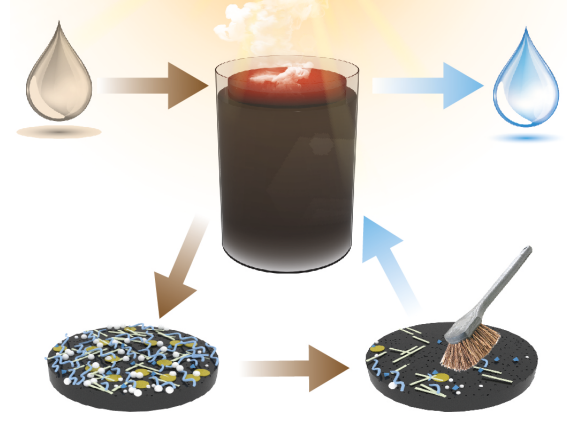

A highly stable and easily regenerable $\mathrm{SiC}-\mathrm{C}$ composite as an efficient photothermal material is designed for practical solar-driven water evaporation. 